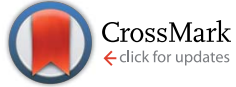

Cite this: J. Mater. Chem. A, 2015, 3 , 4855

Received 10th November 2014 Accepted 23rd January 2015

DOI: $10.1039 / c 4 t a 06070 a$

www.rsc.org/MaterialsA

\section{Using intermolecular interactions to crosslink PIM- 1 and modify its gas sorption properties $\dagger$}

\author{
Tom O. McDonald, ${ }^{\star a}$ Riaz Akhtar, ${ }^{\mathrm{b}}$ Cher Hon Lau, ${ }^{\mathrm{c}}$ Thanchanok Ratvijitvech, ${ }^{\mathrm{a}}$ \\ Ge Cheng, ${ }^{a}$ Rob Clowes, ${ }^{d}$ Dave J. Adams, ${ }^{a}$ Tom Hasell ${ }^{a}$ and Andrew I. Cooper ${ }^{a}$
}

The intermolecular interactions between the "polymer of intrinsic microporosity" PIM-1 and polycyclic aromatic hydrocarbons (PAHs) have been investigated with the aim of modifying the gas sorption and physical properties. Mixing PIM-1 with selected PAHs resulted in rapid precipitation of polymer. Blending PIM-1 with pyrene had a significant effect of the gas sorption properties of the resulting films; dramatically reduced $\mathrm{N}_{2}$ uptake $\left(77 \mathrm{~K}\right.$ ), whilst $\mathrm{CO}_{2}$ uptake at $298 \mathrm{~K}$ was only slightly reduced. A gateopening behaviour was also observed for the $\mathrm{N}_{2}$ gas sorption $(77 \mathrm{~K})$, which was related to the pyrene content of the blend. Using an electron-donating PAH as the additive resulted in a stronger interaction. By exploiting a post-modification strategy after PIM-1 film formation, the absorption of either pyrene or 1-aminopyrene produced films with higher elastic moduli and greatly improved $\mathrm{CO}_{2} / \mathrm{N}_{2}$ gas sorption selectivities $(293 \mathrm{~K})$. Single gas permeability measurements revealed that while the 1-aminopyrene modified film possessed reduced $\mathrm{CO}_{2}$ permeability, it possessed enhanced $\mathrm{CO}_{2} / \mathrm{N}_{2}$ selectivity. Importantly, the ageing of the permeability was halted over the 50 days tested, likely due to the physical crosslinking of the polymer chains by 1 -aminopyrene.

\section{Introduction}

Polymers of intrinsic microporosity (PIMs) have been the subject of extensive research due to their solution-processability and microporous nature. ${ }^{1,2}$ These polymers possess high free volumes mainly in the microporous range, which is attributed to the contortion of the rigid backbone about a spiro-carbon centre, leading to inefficient packing of the polymer chains. ${ }^{3} \mathrm{~A}$ range of PIMs have been prepared utilising an assortment of different monomers ${ }^{1}$ but PIM-1 (Fig. 1), the first example of its type, is still regarded as one of the most promising materials for gas separation. ${ }^{4}$ PIM-1 is a linear polymer formed by the

${ }^{a}$ Department of Chemistry, University of Liverpool, Crown Street, Liverpool, L69 7ZD, UK. E-mail:Thomas.McDonald@liverpool.ac.uk

${ }^{b}$ Centre for Materials and Structures, School of Engineering, University of Liverpool, Liverpool L69 3GH, UK

${ }^{c}$ CSIRO Division of Materials Science and Engineering, Private Bag 33, Clayton South MDC, VIC 3169, Australia

${ }^{d}$ Centre for Materials Discovery, University of Liverpool, Crown Street, Liverpool, L69 $7 Z D, U K$

$\dagger$ Electronic supplementary information (ESI) available: The ESI contains further photographs investigating the precipitation of PIM-1 into solutions of pyrene. Dynamic light scattering analysis of PIM-1 precipitation with pyrene, gas sorption data comparing the effect of length of time used for the methanol soaking of PIM-1 films, a photograph of PIM-1 and PAH blends dried to give films, UV-Vis data for the relationship between pyrene concentration in solution and the amount of pyrene absorbed by the PIM-1 film, visual and SEM comparison of post-modified PIM-1 films, and transmission UV-Vis of PIM-1 films post-modified with pyrene. See DOI: 10.1039/c4ta06070a condensation of 5,5,6,6-tetrahydroxy-3,3,3,3-tetramethyl-1,1spirobisindane with tetrafluoroterephtalonitrile. ${ }^{5}$ This polymer is soluble in a number of common volatile solvents ${ }^{6}$ offering easy solution processing into films and has been the subject of a great deal of studies. ${ }^{4,7-17}$ PIM-1 is interesting for applications in gas separation membranes due to its high permeability and moderate selectivity. ${ }^{18}$ Recently, a range of approaches have been published showing a further enhancement of the selectivity of membranes based on PIM-1. These modification approaches generally fall into two categories: modification of the polymer backbone, or crosslinking PIM-1 to form a network. Modifications of the polymer backbone include the hydrolysis of the nitriles to carboxylic acids, ${ }^{8}$ synthesis of analogues of PIM-1 by substituting the nitrile group on the tetrafluoroterephthalonitrile monomer with different sulfone-based functionalities, ${ }^{7}$ converting the nitrile groups of PIM-1 to thioamide groups ${ }^{11}$ amidoxime groups ${ }^{19}$ or primary amines ${ }^{20}$ and incorporation of the $\mathrm{CO}_{2}$-philic tetrazole groups to PIM-1 by<smiles>CC1(C)Oc2cc3c(cc2O1)C1(CC(C)(C)c2cc4c(cc21)Oc1c(C#N)c(C#N)c(C#N)c(c1C#N)C4)CC3(C)C</smiles>

Fig. 1 Repeat unit of PIM-1. 


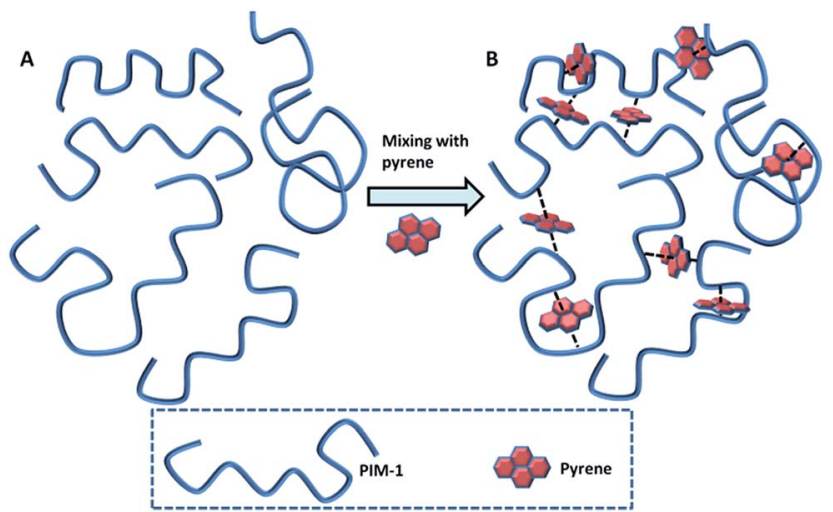

Fig. 2 Cartoon representation of physical crosslinking induced by mixing with pyrene additive. (A) Independent rigid PIM-1 polymer chains. (B) Intermolecular and intramolecular physical crosslinking of the PIM-1 chains with pyrene.

reacting the nitrile groups with sodium azide. ${ }^{17}$ Crosslinking approaches have included thermal crosslinking of the polymer by the trimerisation of the nitrile groups to triazine, ${ }^{13} \mathrm{UV}$ radiation has been used to give an increase in the selectivity, firstly by Chung and co-workers who suggested that the modification in behaviour was due to chain rearrangement ${ }^{21}$ while more recently Sivaniah and co-workers attributed the modification in properties to a photo-oxidative surface modification of the membrane.${ }^{16}$ It has been proposed that crosslinking PIM-1 may have the effect of reducing the pore size of the material thus improving its selectivity. Sivaniah and co-workers have recently demonstrated the use of thermal oxidative crosslinking to tune the properties of PIM-1 by modifying the micropore structure. $^{22}$

An interesting method of adjusting the properties of a PIM-1 membrane without modifying the polymer itself is to use additives. Mixed matrix approaches ${ }^{23}$ have been shown to be useful in enhancing the gas transport properties of PIM-1 and a range of different materials have been produced by blending PIM-1 with (amongst others) inorganic fillers, ${ }^{24}$ cage nanocrystals, ${ }^{25}$ porous nanoparticles, ${ }^{26}$ carbon nanotubes ${ }^{27}$ and other polymers. ${ }^{28}$ Chemical crosslinking with blended polymers has been found to enhance the separation properties. ${ }^{29,30}$ For unrelated polymer systems, supramolecular interactions between polymers have been exploited to provide physical crosslinking used in self-healing polymers. ${ }^{31}$ An example of this approach is the use of charge transfer interactions between electron-rich pyrenyl end-groups and electron-deficient naphthalene diimide units. ${ }^{32,33}$ Here, we propose a novel strategy to modify the properties of PIM-1 by combining the concepts of blending and crosslinking; an additive will be added to the polymer with the aim of facilitating crosslinking via physical intermolecular interactions. Given the relatively electron-deficient structure, we hypothesised PIM-1 might interact favourably with electron-rich polycyclic aromatic hydrocarbons (PAHs) (Fig. 2). We have investigated the effect of mixing PIM-1 with a range of PAHs on the gas sorption and mechanical properties of the resulting blends.

\section{Materials and methods}

\section{Materials}

All materials were used without further purification, $3,3,3^{\prime}, 3^{\prime}-$ tetramethyl-1-1" ${ }^{\prime \prime}$-spirobisindane-5,5',6, $6^{\prime}$-tetrol was purchased from Apollo (UK), 2,3,5,6-tetrafluorophthalonitrile was purchased from Alfa Aesar (UK) and $\mathrm{K}_{2} \mathrm{CO}_{3}$ was supplied by Fisher (UK). All other materials were purchased from SigmaAldrich (UK).

\section{Synthesis of PIM-1}

PIM-1 was synthesised using the procedure described by Budd et al. ${ }^{5}$ Briefly, $\mathrm{K}_{2} \mathrm{CO}_{3}$. $(963.2 \mathrm{mmol}, 133.12 \mathrm{~g}$ ) was added to a solution of $3,3,3^{\prime}, 3^{\prime}$-tetramethyl-1-1' $1^{\prime \prime}$-spirobisindane5,5',6,6'-tetrol (120.4 mmol, $40.99 \mathrm{~g})$ and 2,3,5,6-tetrafluorophthalonitrile $(120.4 \mathrm{mmol}, 24.09 \mathrm{~g})$ in dry DMF (1200 $\mathrm{mL})$. The reaction was stirred at $65^{\circ} \mathrm{C}$ for 72 hours. After cooling to room temperature, water $(1200 \mathrm{~mL})$ was added. The product was collected by filtration before being reprecipitation from $\mathrm{CHCl}_{3}$ into $\mathrm{MeOH}$. The resulting yellow solid was dried under vacuum overnight. The yield was $52.42 \mathrm{~g}(94 \%)$. The polymer was analysed by ${ }^{1} \mathrm{H}$-NMR, elemental analysis and GPC (Viscotek system employing OmniSEC 4.6 software, TDA Model 302 (rightangle \& low-angled light scattering, refractive index, ultra-violet and viscometer detectors coupled to a gpcMAX integrated solvent and sample delivery module). The system was fitted with a ViscoGEL HHR-H guard column and two ViscoGEL GMHHR$\mathrm{H}$ columns, at a flow rate of $1 \mathrm{~mL} \mathrm{~min}{ }^{-1}$, using chloroform). ${ }^{1} \mathrm{H}-$ NMR $\left(400 \mathrm{MHz}, \mathrm{CDCl}_{3}\right): \delta_{\mathrm{H}} 1.31(6 \mathrm{H}, \mathrm{s}), 1.37(6 \mathrm{H}, \mathrm{s}), 2.24(4 \mathrm{H}$, br. d), $6.42(2 \mathrm{H}, \mathrm{s}), 6.81(2 \mathrm{H}, \mathrm{s})$. Elemental analysis: $\mathrm{C}_{29} \mathrm{H}_{20} \mathrm{~N}_{2} \mathrm{O}_{4}$. Theory: C 75.64, H 4.38, N 6.08. Found: C 73.26, H 4.27, N 5.96. GPC: $M_{\mathrm{n}} 70740 \mathrm{Da}, M_{\mathrm{w}} 134641 \mathrm{Da}, M_{\mathrm{w}} / M_{\mathrm{n}} 1.90$.

\section{Precipitation experiments}

The precipitation of PIM-1 was investigated in a number of PAH solutions. Solutions of PAHs were prepared at $50 \mathrm{mg} \mathrm{mL}^{-1}$ in dichloromethane (DCM), or if this was above the solubility limit of the PAH a saturated solution was prepared and the supernatant was used. A solution of PIM-1 was prepared in DCM at 50 $\mathrm{mg} \mathrm{mL}{ }^{-1}$. Three drops $(\approx 0.2 \mathrm{~mL})$ of this solution were added from a $1 \mathrm{~mL}$ syringe to each of the PAH solutions. Photographs were taken of samples approximately 10 minutes after PIM-1 addition using a light box (Digital imaging box DIB-1612).

\section{Preparation of PIM-1 and pyrene blends}

PIM-1 and pyrene blends were produced as follows. Solutions of PIM-1 or pyrene were prepared at $50 \mathrm{mg} \mathrm{mL} \mathrm{m}^{-1}$ in DCM. To the appropriate amount of pyrene solution in a $4 \mathrm{~mL}$ vial the PIM-1 solution was added, achieving the desired composition with a total volume of $2 \mathrm{~mL}$. The samples were left for 48 hours for the DCM to fully evaporate, before being placed under vacuum at $65{ }^{\circ} \mathrm{C}$ for 18 hours. The polymer blends were then immersed in methanol for 3 hours which was then decanted prior to the films being dried under vacuum again at $65^{\circ} \mathrm{C}$ for 4 hours. The samples were then broken into smaller pieces and removed 
from the vials for gas sorption analysis. The pyrene content of the film was calculated from the initial amount of pyrene solution added.

\section{Post modification of PIM-1 films with pyrene or 1- aminopyrene}

Post-modification of PIM-1 films with pyrene or 1-aminopyrene was carried out by the following method. Firstly a PIM-1 film was produced by adding $16-18 \mathrm{~g}$ of PIM-1 solution in DCM at 50 $\mathrm{mg} \mathrm{mL}^{-1}$ in a $200 \mathrm{~mL}$ evaporation dish, which was then left overnight for the DCM to fully evaporate. Pieces of this film PIM-1 were then used to test the effect of different pyrene or 1aminopyrene content in post-modified films. A control treatment (no modification) was carried out with methanol alone. Four concentrations of pyrene or 1-aminopyrene in methanol were tested up to $7 \mathrm{mg} \mathrm{mL} \mathrm{m}^{-1}$. In all cases, the films were immersed in these methanolic solutions of pyrene or 1-aminopyrene for 3 hours prior to being dried under vacuum at $65^{\circ} \mathrm{C}$ for 4 hours.

\section{Dynamic light scattering analysis}

The aggregation of PIM-1 and pyrene was analysed by dynamic light scattering (DLS). PIM-1 was added to a quartz cuvette at $0.39 \mathrm{mg} \mathrm{mL}^{-1}$ in DCM, to which aliquots of pyrene in DCM (at a concentration of $50 \mathrm{mg} \mathrm{mL}^{-1}$ ) were then added (to achieve a final overall concentration of pyrene of up to $7.6 \mathrm{mg} \mathrm{mL}^{-1}$ ). The sample was mixed prior to DLS analysis. The scattering of the solutions were measured at a temperature of $25{ }^{\circ} \mathrm{C}$ using a Malvern Zetasizer Nano ZS equipped with a $4 \mathrm{~mW}$ He-Ne, 633 $\mathrm{nm}$ laser. Malvern Zetasizer software version 6.20 was used for data analysis.

\section{UV-Vis characterisation of PIM-1 films post-modified with pyrene or 1-aminopyrene films}

The UV-Vis absorption spectra of unmodified and post-modified PIM-1 films were obtained in transmission using a Shimadzu UV-2550 UV-Vis spectrophotometer running the UVProbe software, version 2.34. All spectra were measured from 190-800 nm, with scan speed set to fast and using a slit width of $5 \mathrm{~nm}$.

\section{Characterising pyrene or 1-aminopyrene content in post- modified PIM-1 films}

The pyrene or 1-aminopyrene content of the post-modified PIM1 films was determined by a UV-Vis mass balance approach. A known mass of PIM-1 film was soaked in a known concentration of additive (either pyrene or 1-aminopyrene). After 3 hours, the PIM-1 film was removed and the absorbance of the solution was measured (Shimadzu UV-2550 UV-Vis spectrophotometer) at $332 \mathrm{~nm}$ or $282 \mathrm{~nm}$ (for pyrene or 1-aminopyrene respectively). The concentration was determined by comparison to calibration from known standards of pyrene or 1-aminopyrene. Any reduction in concentration of the additive was assumed to have been a result of absorption into the PIM-1 film.

\section{Scanning electron microscopy (SEM) of PIM-1 films}

Scanning electron microscopy (SEM) analysis was used to analyse the cold-fractured (liquid $\mathrm{N}_{2}$ ) edges of PIM-1 unmodified and post-modified films and measure the film thickness. Samples of the films were fixed onto the aluminium stubs with carbon tabs perpendicular to the surface of the stub. The samples were then gold coated for 3 minutes at $20 \mathrm{~mA}$ using a sputter-coater (EMITECH K550X) prior to imaging. SEM images were recorded using a Hitachi S- $4800 \mathrm{FE}-\mathrm{SEM}$ at $3 \mathrm{kV}$. The mean film thickness was determined by imaging 7 samples of the film, the thickness of the each sample of film was measured in at least 6 places along the film using Image 1.46r. The mean thickness of the film was determined from at total of 137 measurements, providing a value of $49.0 \mu \mathrm{m}$ with a standard deviation of $5.0 \mu \mathrm{m}$.

\section{Nanoindentation analysis}

Nanoindentation was carried out using an Agilent nanoindenter G200 (Keysight Technologies, Chandler, AZ, USA) instrument with an ultra-low load dynamic contact module indentation head (DCM-I). The indentations were performed at ambient temperature, aligned normal to the film surface, using a Berkovich tip with a $20 \mathrm{~nm}$ radius. The film samples were adhered to aluminium pucks using adhesive pads (STKYDOT, Bruker, Coventry, UK). The continuous stiffness measurement option ${ }^{34}$ was used at a frequency of $75 \mathrm{~Hz}$ for the testing. Each indent was made in the film samples up to a maximum depth of $300 \mathrm{~nm}$ of a total film thickness of $49 \mu \mathrm{m}$. A Poisson's ratio of 0.3 was assumed in order to calculate the elastic modulus. 36 indentations were made on each sample.

\section{Gas sorption analysis}

Initial nitrogen isotherm analyses for the PIM-1 pyrene blends at $77 \mathrm{~K}$ were obtained on a Micromeritics ASAP 2420 instrument using an equilibration interval of 30 seconds for relative pressures less than 0.01 and 15 seconds equilibration interval for all other pressures. Prior to analysis, samples were degassed under vacuum for 900 minutes at $80{ }^{\circ} \mathrm{C}$. The free space measurements were carried out after analysis. The cycled isotherm $\mathrm{N}_{2}$ measurements were obtained using a Micromeritics ASAP 2020 with an equilibration interval of 30 seconds for relative pressures less than 0.15 and 20 seconds equilibration interval for all other pressures. An in situ degas was carried out for 4 hours at $80{ }^{\circ} \mathrm{C}$ before analysis. Free space measurements were carried out after analysis. The $\mathrm{N}_{2}$ and $\mathrm{CO}_{2}$ gas sorption measurements at $298 \mathrm{~K}$ were obtained on a Micromeritics ASAP 2020 equipped with a HAAKE Phoenix II circulator. The equilibration intervals were as follows $>1.33 \mathrm{mbar}=45$ seconds, $1.33-13.33 \mathrm{mbar}=30$ seconds, 13.33-133.3 mbar $=25$ seconds, 133.3-1100 $\mathrm{mbar}=$ 20 seconds. The free space measurements were carried out before analysis as is usual. Gas sorption analysis of the postmodified PIM-1 films was carried out on Micromeritics 3Flex Surface Characterisation Analyser with 3 samples ports each with 100, 10 and 0.1 Torr pressure transducers. Temperature control was achieved using Micromeritics supplied ColdEdge 
Technologies Cryocooler model $\mathrm{CH}-104$ with a sample temperature range of $50 \mathrm{~K}$ to $310 \mathrm{~K}$ with $<0.01 \mathrm{~K}$ drift. For the $\mathrm{N}_{2}$ at $77 \mathrm{~K}$ analysis an in situ degas was carried out for 180 minutes at $80^{\circ} \mathrm{C}$ prior, and the equilibration intervals for the following relative pressures were used $>0.001=45$ seconds, 0.001-0.01 $=30$ seconds, $0.01-0.1=25$ seconds, $0.1-1=20$ seconds. The free space measurements were carried out after analysis. The $\mathrm{N}_{2}$ and $\mathrm{CO}_{2}$ gas sorption measurements at $293 \mathrm{~K}$ were obtained using the 3Flex using the same settings as used on the ASAP 2020 at $298 \mathrm{~K}$. The $\mathrm{CO}_{2} / \mathrm{N}_{2}$ gas sorption selectivity was calculated using the respective uptakes at 1000 mbar. All gases used in the gas sorption experiments were at least $99.9995 \%$ pure.

\section{Single gas permeability measurements}

The pure gas permeabilities of the PIM-1/PAH films were characterised using a home-made setup outlined in Lau et al.'s recent work. ${ }^{26}$ The pure $\mathrm{N}_{2}$, and $\mathrm{CO}_{2}$ permeabilities were determined using a constant volume and variable pressure method..$^{35}$ Gas permeabilities at 2 atm were determined from the rate of downstream pressure build-up rate $(\mathrm{d} p / \mathrm{d} t)$ obtained when permeation reached a steady state according to the following equation:

$$
P=D \times S=\frac{273 \times 10^{10}}{760} \frac{V L}{A T\left[\frac{P_{2} \times 76}{14.7}\right]}\left(\frac{\mathrm{d} p}{\mathrm{~d} t}\right)
$$

$P$ refers to the permeability of a membrane to a gas and its unit is in Barrer $\left(1\right.$ Barrer $=1 \times 10^{-10} \mathrm{~cm}^{3}(\mathrm{STP})-\mathrm{cm} \mathrm{cm} \mathrm{cm}^{-2} \mathrm{~s}^{-1}$ $\left.\mathrm{cmHg}^{-1}\right),{ }^{7} \mathrm{D}$ is the average effective diffusivity $\left(\mathrm{cm}^{2} \mathrm{~s}^{-1}\right), S$ is the apparent sorption coefficient/solubility $\left(\mathrm{cm}^{3}\right.$ (STP) per $\mathrm{cm}^{3}$ polymer $\mathrm{cmHg}$ ), $V$ is the volume of the downstream chamber $\left(\mathrm{cm}^{3}\right), L$ is the film thickness $(\mathrm{cm})$. A refers to the effective area of the membrane $\left(\mathrm{cm}^{2}\right), T$ is the experimental temperature $(\mathrm{K})$ and the pressure of the feed gas in the upstream chamber is given by $p_{2}$ (psia).

\section{Results and discussion}

Charge-transfer interactions are intermolecular interactions between $\pi$-electron rich (donor) molecules and $\pi$-electrondeficient (acceptor) molecules. We hypothesised that the electron-deficient PIM-1 molecule might undergo charge-transfer with PAHs and that these interactions might lead to modification of the physical properties of the material. Addition of a PIM-1 solution to PAH solutions showed immediate precipitation of the polymer in the cases of pyrene, triphenylene, benzo [a]pyrene or coronene (Fig. 3). In the case of pyrene and benzo [a]pyrene, a slight darkening of the solutions was also observed. No precipitation was observed for any of the other PAHs tested here. There therefore seems to be a requirement for an extended planar conjugated system in order to induce sufficient attraction to the PIM-1 to cause precipitation. Pyrene has previously been shown to form electron donor-acceptor complexes with an electron acceptor molecule. ${ }^{36,37}$ We believe that simple $\pi-\pi$ stacking can be ruled out here as the interaction mechanism because precipitation was not seen for all PAHs. Additionally precipitation was also observed when pyrene was dissolved in benzene, where one would expect significant competition if $\pi-\pi$ stacking were the driving force for interaction (Fig. S1, ESI $\dagger$ ). Mixing the PIM-1 and pyrene solutions resulted in visible precipitation at concentrations of pyrene $\geq 6.25 \mathrm{mg} \mathrm{mL}^{-1}$ (Fig. S2, ESI $\dagger$ ). Further investigation of the precipitation process

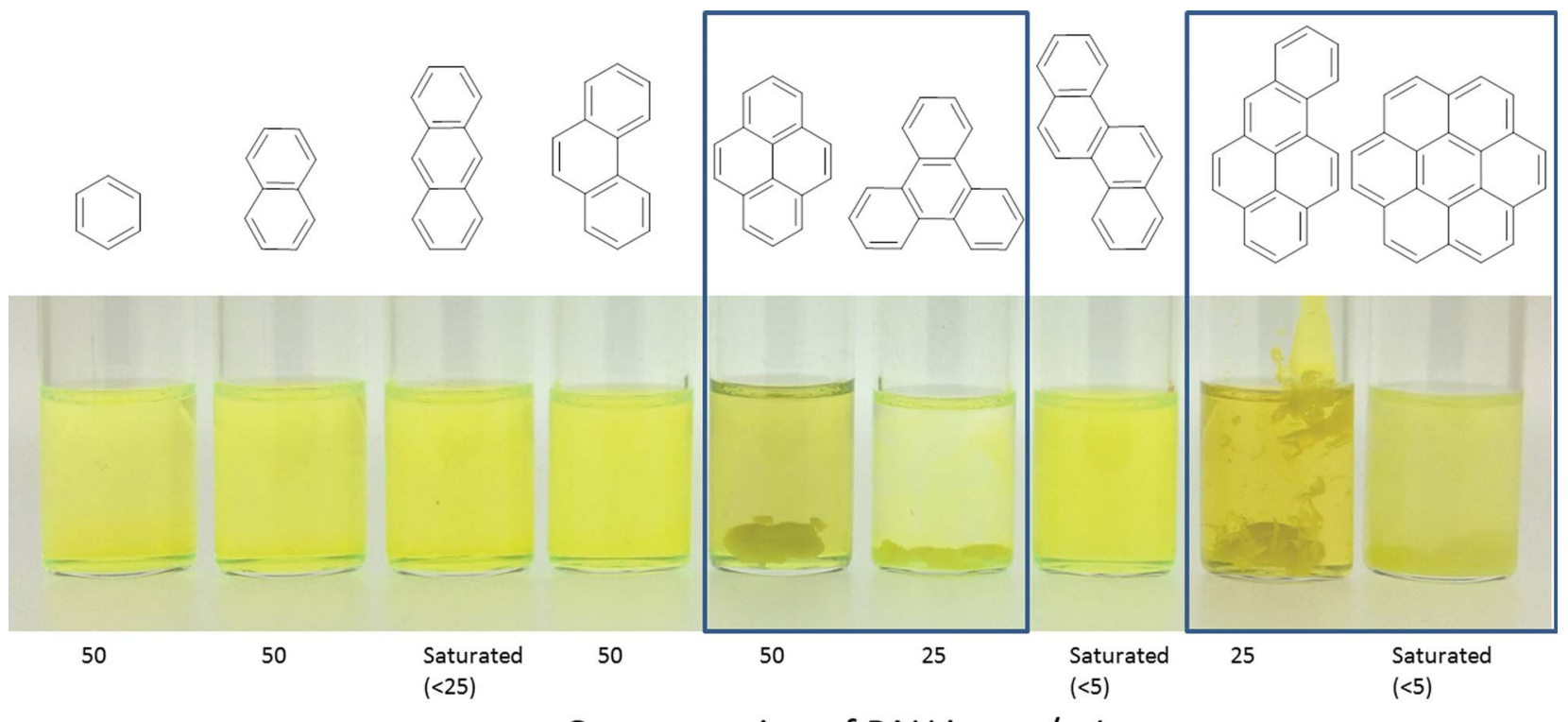

Concentration of PAH in $\mathrm{mg} / \mathrm{mL}$

Fig. 3 Effect of the structure of (poly)cyclic aromatic hydrocarbons on the interaction with PIM-1 solution. Three drops of PIM-1 solution (50 mg $\mathrm{mL}^{-1}$ in DCM) were added to PAH solutions (in at the stated concentration DCM). The cyclic aromatic hydrocarbons and PAHs tested were (from left to right): benzene, naphthalene, anthracene, phenanthrene, pyrene, triphenylene, chrysene, benzo[a]pyrene and coronene. Blue boxes indicate when precipitation was visually observed. 


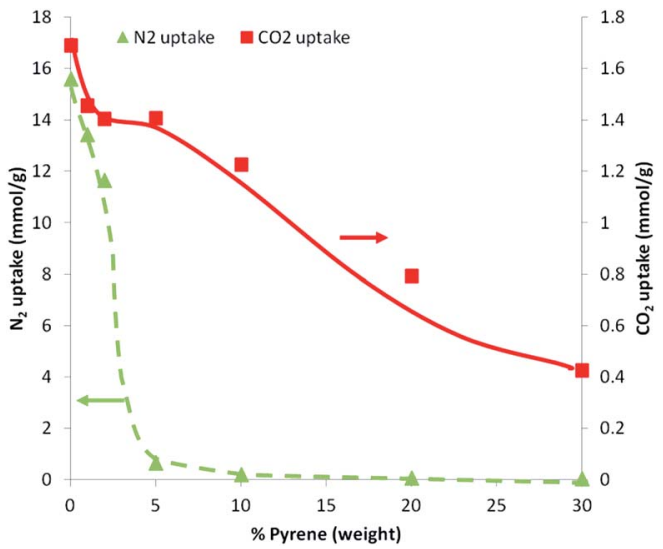

Fig. 4 Gas sorption properties for PIM-1 pyrene blends, nitrogen uptake at 1 bar (obtained from nitrogen isotherms at $77 \mathrm{~K}$ ) and $\mathrm{CO}_{2}$ uptake at 1 bar (at $298 \mathrm{~K}$ ) of PIM-1 and pyrene blends as a function of the composition of the film (trend lines are to guide the eye).

by dynamic light scattering (DLS) showed that aggregation of the PIM-1 polymer chains occurred at much lower concentrations (PIM-1 at $0.39 \mathrm{mg} \mathrm{mL}^{-1}$ with pyrene at concentrations above $0.2 \mathrm{mg} \mathrm{mL}^{-1}$, see Fig. S3, ESI $\dagger$ ). For further experiments, pyrene was selected as the preferred PAH since this showed a strong interaction with PIM-1, whilst also being inexpensive and abundant. These findings suggest that attractive intermolecular interactions between PIM-1 and certain PAHs results in a physical crosslinking of the polymer causing formation of aggregates and at higher concentrations, precipitation of the polymer.

We were interested in modifying the gas sorption and permeation properties of PIM-1 membranes. We hypothesised that the supramolecularly crosslinking PIM-1 with pyrene would allow these properties to be tuned. Therefore, solutions of PIM-1 and pyrene in DCM were mixed at varying ratios (v/v) and then evaporated to dryness to form films blends. Methanol ${ }^{4}$ or ethanol ${ }^{11}$ soaking has been shown to be important in enhancing the uptake of PIM-1 films. Therefore, all PIM-1 and pyrene blends were soaked in methanol for 3 hours (longer soaking times had no effect on the $\mathrm{N}_{2}$ isotherm (see Fig. S4, ESI $\dagger$ )). The 100\% PIM-1 film displayed an isotherm with a Brunauer-Emmett-Teller (BET) surface area ${ }^{38}$ of $686 \mathrm{~m}^{2} \mathrm{~g}^{-1}$, in agreement with the literature value of approximately $720 \mathrm{~m}^{2}$ $\mathrm{g}^{-1} .4$ The effect of blending pyrene with PIM-1 was dramatic; at pyrene compositions $\geq 5 \%$ (w/w), essentially no nitrogen uptake was observed (Fig. 4). At lower pyrene contents in the blend, gate-opening behaviour was seen in the isotherm (see Fig. S5, ESI†). This unusual behaviour is currently not well understood and has been reported for PIM-1 in other work..$^{22,39}$ These steps occurred between relative pressures of $0.25-0.5$ and appear to be related to the amount of pyrene included in the blend; as the pyrene content increased, the pressure at which pore-opening occurred was also increased. While the isotherms indicated that at lower pressures the equilibration interval was not long enough for complete equilibration, the overall data was of sufficient quality to allow direct comparison between gas uptakes of the different blends. The $\mathrm{N}_{2}$ uptakes of the polymer blends showed a dramatic approximately linear decrease with increasing pyrene content from $15.6 \mathrm{mmol} \mathrm{g}^{-1}$ for $100 \%$ PIM-1 to $0.7 \mathrm{mmol} \mathrm{g}^{-1}$ for a blend of PIM-1 containing $5 \%$ pyrene (Fig. 4). Whilst there was a marked reduction in the nitrogen uptakes of the PIM- 1 and pyrene blends, the effect of incorporating pyrene into the film on the $\mathrm{CO}_{2}$ uptake at $298 \mathrm{~K}$ was much less pronounced; $\mathrm{CO}_{2}$ uptake gradually reduced with increasing pyrene content (Fig. 4).

The dramatic reduction in nitrogen uptake coupled with only a slight loss in $\mathrm{CO}_{2}$ uptake with $5 \%$ pyrene in the film suggests that these films may offer higher selectivity for $\mathrm{CO}_{2}$ over $\mathrm{N}_{2}$ and as such may possess superior gas separation characteristics. The gas sorption results of PIM-1 and pyrene blends suggests that the addition of pyrene reduces the pore size of the material. Given the larger size of the $\mathrm{N}_{2}$ molecule (3.6 A) than $\mathrm{CO}_{2}(3.3 \AA)$ it is likely that increased crosslinking would narrow the interconnected cavities present in PIM- $1^{22}$ making the diffusion $\mathrm{N}_{2}$ into the materials more difficult.

In order to further investigate the observed pore-opening behaviour observed in the $\mathrm{N}_{2}$ isotherms, cycles of adsorption and desorption were carried out. A PIM-1 (99\%) and pyrene (1\%) blend was analysed for 3 cycles (Fig. 5A). In these experiments
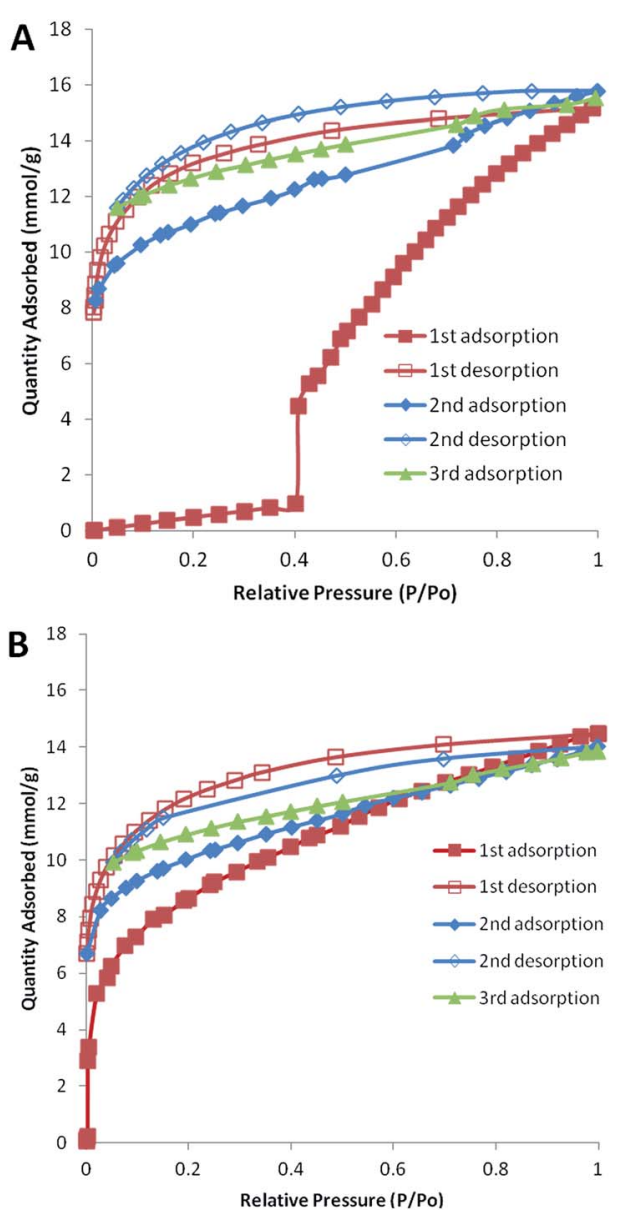

Fig. 5 Cycled adsorption and desorption nitrogen isotherms (77 K). (A) PIM-1 (99\%) and pyrene (1\%) blend film. (B) PIM-1 film (100\%). 


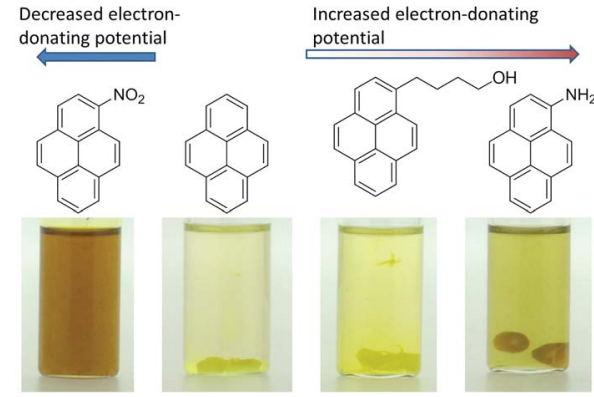

Fig. 6 Effect of addition of changing the electron donating potential of pyrene on the interaction with PIM-1. The image shows the solutions of pyrene derivatives (50 mg mL $\mathrm{m}^{-1}$ in DCM) after the addition of three drops of PIM-1 at $50 \mathrm{mg} \mathrm{mL}^{-1}$ (in DCM).

the equilibration intervals were increased in order to address the incomplete equilibration observed in our earlier $\mathrm{N}_{2}$ isotherms (Fig. S5, ESI $\dagger$ ). The first adsorption displayed no significant gas uptake until a relative pressure of 0.40 at which a step increase was observed, followed by an increase in $\mathrm{N}_{2}$ adsorption with pressure up to a maximum uptake of 15.5 mmol g ${ }^{-1}$ (Fig. 5A). Subsequent adsorption isotherms did not display this step increase, although some hysteresis was observed as has been noted elsewhere for PIM-1. ${ }^{22,40,41}$ This experiment indicated that the degassing procedure (under vacuum at $80{ }^{\circ} \mathrm{C}$ ) may have resulted in kinetic pore closure assisted by the physical crosslinking of the pyrene. Once the pores had opened, further desorption and adsorption isotherms showed much higher uptakes without the step increase. Weber and co-workers have suggested that within porous polymers the pores with restricted access will not open until there is sufficient solvation pressure.$^{40}$ For comparison a cycled isotherm was obtained for a 100\% PIM-1 sample. This experiment displayed the expected type I isotherm with hysteresis and no pore-opening behaviour (Fig. 5B). Our data suggests that raising the pyrene content in the PIM-1 blends produces pores that require higher solvation pressures to open; this may be due to the stronger physical crosslinking interactions.

In order to determine whether stronger intermolecular interactions between the PIM-1 and pyrene derivatives would have a greater influence on the gas sorption properties, we screened three different derivatives of pyrene with different electron donating potential. Upon the addition of the solution of PIM-1 to a solution of each pyrene derivative, precipitation was observed for 1-pyrenebutanol and 1-aminopyrene, both of which present greater electron-donating potential than pyrene (Fig. 6).

When PIM-1 was added to 1-nitropyrene with weaker electron-donating ability than pyrene, no precipitation was observed (Fig. 6). 1-Aminopyrene demonstrated the strongest interaction; the drops of PIM-1 gelled immediately on contact with the 1-aminopyrene solution forming hollow spheroids. Additionally, a strong colour change of the precipitate was observed, indicative of charge transfer. ${ }^{37}$ These data provide

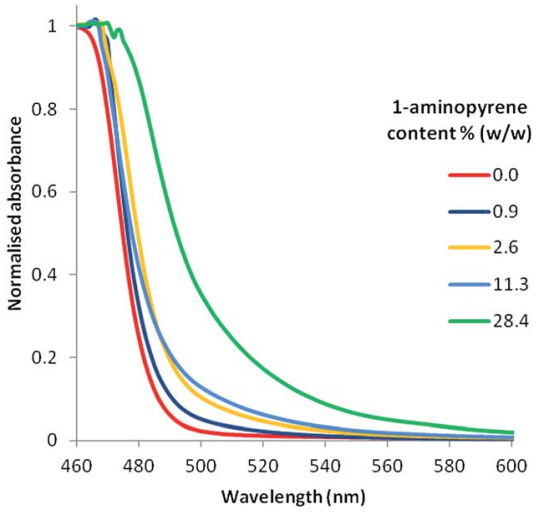

Fig. 7 UV/Vis spectra for PIM-1 films post-modified with increasing amounts of aminopyrene.

further evidence for a physical crosslinking of the PIM-1 chains via charge transfer.

One of the main attractive properties of PIM-1 is its ability to form coherent films. ${ }^{1}$ The blending of PIM-1 and the pyrene additives tended to produce more heterogeneous films due to the formation of intermolecular aggregates during drying (Fig. S6, ESI†). To address this, we developed a method to postmodify the films with pyrene or 1-aminopyrene after film formation, from here-on termed post-modification. This approach exploited the low solubility of pyrene in methanol (up to $\left.7.36 \mathrm{mg} \mathrm{mL}^{-1}, 0.0364 \mathrm{M}\right)^{42}$ to allow incorporate the activation step (soaking in methanol) with modification. PIM-1 films were soaked in methanolic solutions of either pyrene or 1-aminopyrene at a range of concentrations (up to $7 \mathrm{mg} \mathrm{mL}^{-1}$ ). Pyrene or 1 -aminopyrene absorption by the films was then calculated by measuring the decrease in the pyrene/1-aminopyrene concentration in solution by UV/Vis. The amount of pyrene absorbed by a known amount of PIM-1 film was found to have a linear relationship (over the range tested) with the concentration of the pyrene in solution (see Fig. S7, ESI †). Visual inspection of the PIM-1 films post-modified with pyrene showed uniform

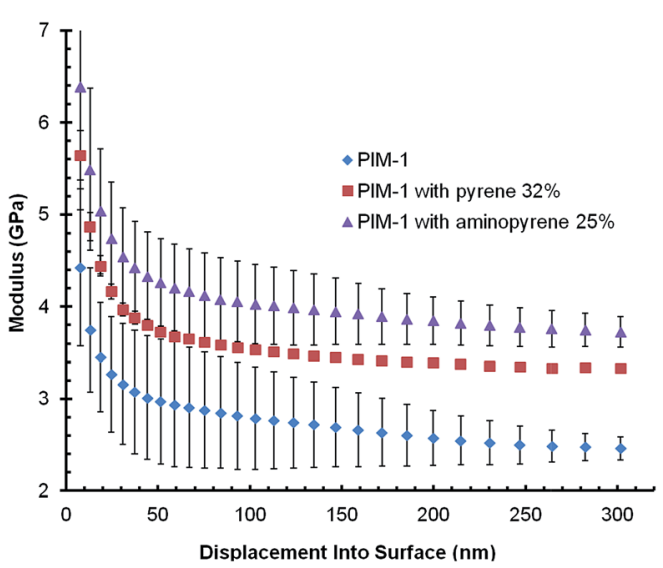

Fig. 8 Comparison of nanoindentation data for unmodified PIM-1 films and PIM-1 films post-modified with either $32 \%$ pyrene or $25 \% 1$ aminopyrene. 

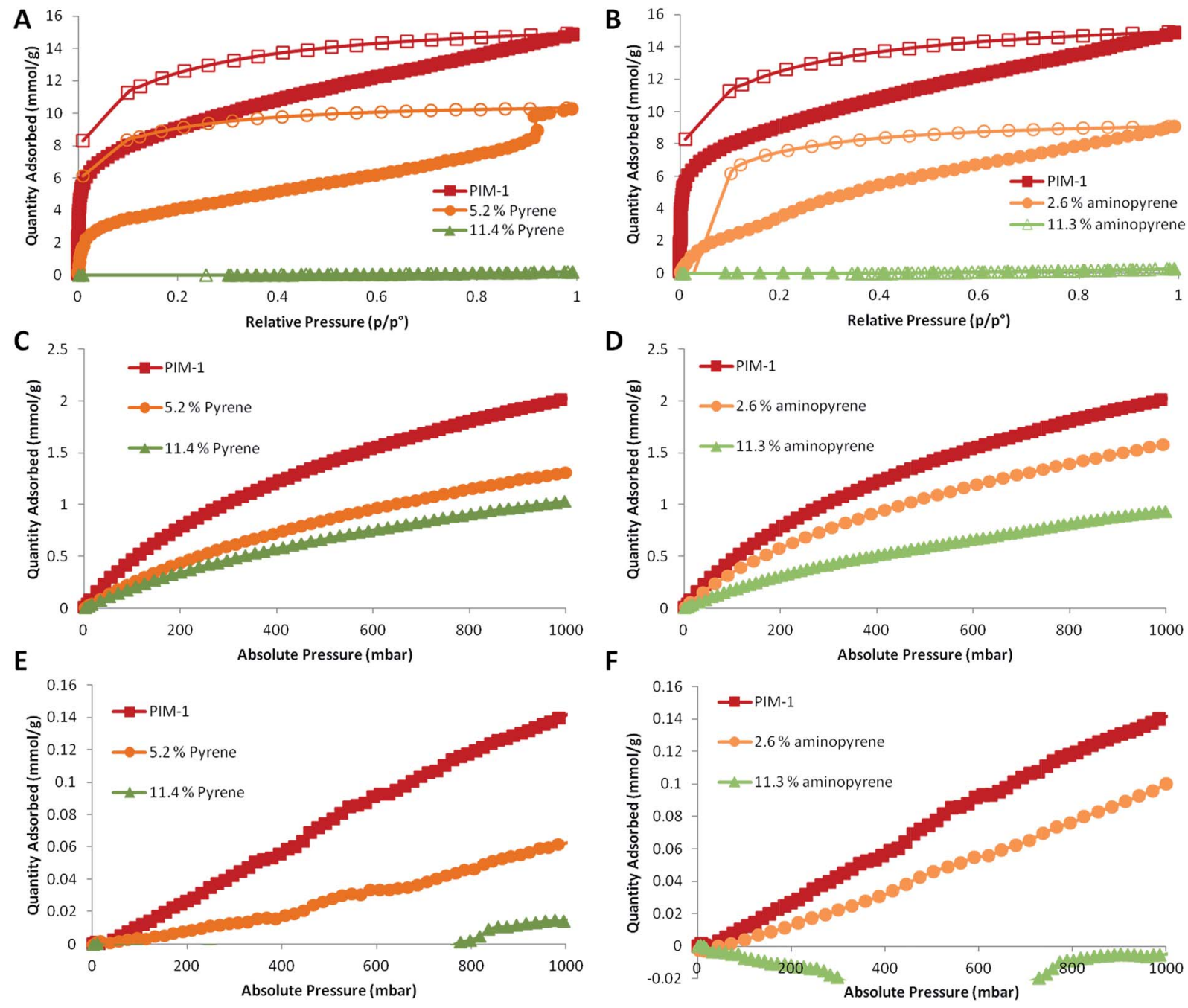

Fig. 9 Gas sorption properties of PIM-1 films post-treated with methanolic pyrene solutions or methanolic aminopyrene solutions. (A) \& (B) Nitrogen isotherms (77 K) (legend details the additive content) for pyrene and aminopyrene. (C) \& (D) $\mathrm{CO}_{2}$ isotherms ( $293 \mathrm{~K}$ ) (legend details the additive content) for pyrene and aminopyrene. (E) \& (F) Nitrogen isotherms (293 K) (legend details the additive content) for pyrene and aminopyrene.

samples with no apparent difference between the different pyrene contents (Fig. S8, ESI $\dagger$ ). SEM analysis of a cold-fractured edge of both unmodified PIM-1 film and a film post-modified with pyrene did not reveal any obvious differences (Fig. S9, ESI†े). Charge-transfer interactions typically display changes in the photophysical properties of the materials with the emergence of a charge-transfer band $(400-650 \mathrm{~nm}) \cdot{ }^{37}$ In the case of the PIM-1 film post-modified with pyrene we observed no apparent charge-transfer band (Fig. S10, ESI $\dagger$ ). We note that other studies have shown that charge-transfer absorption bands are not always present ${ }^{37}$ or are very weak. ${ }^{36}$ However, the UV-Vis absorption of the PIM-1 films post-modified with 1-aminopyrene displayed a more prominent charge-transfer band as a broadening from $500-550 \mathrm{~nm}$ in the UV-Vis spectra of the film (Fig. 7). As the amount of 1-aminopyrene incorporated into the film increased, a broader charge transfer band was found.

To probe the mechanical properties of post-modified films we used nanoindentation. This technique has been used elsewhere to investigate crosslinking in PIM-1 films, with higher crosslinking densities leading to higher elastic moduli. ${ }^{16,22}$ These studies found the elastic modulus of PIM-1 (at a displacement of $100 \mathrm{~nm}$ ) to be between 2.6 and $4.1 \mathrm{GPa}$ (ref. 16 and 22) in agreement with our value of $2.8 \mathrm{GPa}$ for unmodified PIM-1. We found that post-modification of PIM-1 with both pyrene-based additives produced films with higher elastic moduli, 3.5 GPa and 4.0 GPa for pyrene or 1-aminopyrene modification respectively (Fig. 8). Interestingly, the post-modification of PIM-1 with 1-aminopyrene led to a greater increase in the modulus than pyrene. These nanoindentation results present further evidence for stronger interactions between the PIM-1 polymer chains and pyrene-based additives provides a crosslinking effect, resulting in stiffer films.

The PIM-1 films post-modified with varying amounts of pyrene or 1-aminopyrene additives were then analysed by $\mathrm{N}_{2}$ and $\mathrm{CO}_{2}$ gas sorption. The post-modification of PIM-1 films with pyrene additives had a similar effect on the gas sorption 
Table 1 Summary of data for the gas sorption properties pf PIM-1 films post-modified with methanolic pyrene or 1-aminopyrene solutions at 1000 mbar

\begin{tabular}{|c|c|c|c|c|c|c|}
\hline Sample & $\begin{array}{l}\mathrm{N}_{2} \text { uptake } \\
\left(\mathrm{mmol} \mathrm{g}^{-1}\right) 77 \mathrm{~K}\end{array}$ & $\begin{array}{l}\mathrm{CO}_{2} \text { uptake } \\
\left(\mathrm{mmol} \mathrm{g}^{-1}\right) 293 \mathrm{~K}\end{array}$ & $\begin{array}{l}\mathrm{N}_{2} \text { uptake } \\
\left(\mathrm{mmol} \mathrm{g}^{-1}\right) 293 \mathrm{~K}\end{array}$ & $\begin{array}{l}\text { Selectivity } \mathrm{CO}_{2} / \mathrm{N}_{2} 293 \\
\mathrm{~K}\end{array}$ & Additive & $\begin{array}{l}\text { Additive content } \\
\text { in film (weight } \% \text { ) }\end{array}$ \\
\hline 1 & 14.86 & 2.04 & 0.14 & 14 & None & 0.0 \\
\hline 3 & 0.20 & 1.05 & 0.02 & 65 & Pyrene & 11.4 \\
\hline 4 & 9.07 & 1.58 & 0.10 & 16 & Aminopyrene & 2.6 \\
\hline 5 & 0.29 & 0.95 & $0^{a}$ & - & Aminopyrene & 11.3 \\
\hline
\end{tabular}

${ }^{a}$ A negative uptake was measured due to pressure transducer inaccuracy at very low gas uptake.

properties as the blending approach; the inclusion of pyrene or 1-aminopyrene in the film greatly reduced the nitrogen uptake at $77 \mathrm{~K}$ (Fig. 9A \& B), although no pore-opening steps were observed. When the film content was $11.4 \%$ pyrene or $11.3 \% 1$ aminopyrene, essentially no $\mathrm{N}_{2}$ uptake occurred at $77 \mathrm{~K}$. The data suggested that 1-aminopyrene might have a stronger effect on reducing the $\mathrm{N}_{2}$ uptake than pyrene. Less $\mathrm{N}_{2}$ uptake was observed for the 2.6\% 1-aminopyrene film (Fig. 9B) than 5.2\% pyrene film (Fig. 9A). As with the PIM-1 pyrene blends, the inclusion of pyrene in the films had a much lower effect on the $\mathrm{CO}_{2}$ uptake of the films (Fig. 9C \& D). The uptake was reduced with increasing pyrene content, although an uptake of 1.05 mmol $\mathrm{g}^{-1}$ was still obtained for the highest pyrene loading tested (11.4\%) (Fig. 9C). Post-modification with 1-aminopyrene produced very similar values for gas uptake (Fig. 9D). The highest 1-aminopyrene content film (11.3\%) showed a $\mathrm{CO}_{2}$ uptake of $0.95 \mathrm{mmol} \mathrm{g}^{-1}$. As expected, the $\mathrm{N}_{2}$ uptakes at $293 \mathrm{~K}$ (Fig. 9E \& F) were substantially lower than those at $77 \mathrm{~K}$, an unmodified PIM-1 film displayed maximum uptake of 0.14 mmol $\mathrm{g}^{-1}$.

As with the other gas sorption experiments, increasing the amount of either pyrene or 1-aminopyrene in the PIM-1 films reduced the amount of gas adsorption by the films. At the highest content of additives $\left(\approx 11 \%\right.$ ), very limited $\mathrm{N}_{2}$ uptake was measured $\left(0.02 \mathrm{mmol} \mathrm{g}^{-1}\right)$ for post-modification with pyrene (Fig. 9E), while for 1-aminopyrene no uptake was observed (Fig. 9F) (the recorded negative adsorption was a result of pressure transducer drift). For direct comparison, the overall uptakes at 1 bar for all the samples for both $\mathrm{N}_{2}$ (at $77 \mathrm{~K}$ and 293 $\mathrm{K}$ ) and $\mathrm{CO}_{2}\left(\right.$ at $293 \mathrm{~K}$ ) are summarised in Table 1 . The $\mathrm{CO}_{2} / \mathrm{N}_{2}$ gas sorption selectivities demonstrated that increasing the additive content within PIM-1 film resulted in dramatically higher selectivity for $\mathrm{CO}_{2}$ over $\mathrm{N}_{2}$ compared to $100 \%$ PIM-1 film. Overall, the gas sorption experiments reveal that the selectivity of PIM-1 films may be enhanced using a post-modification strategy with either pyrene or 1-aminopyrene additives, this behaviour is likely driven by reduction in the pore size of the polymer due to the physical crosslinking provided by the additives.

Having measured the gas sorption properties, we also examined the effect of the additives on the permeability of gases across membranes. The gas permeabilities of the films were analysed by a constant volume and variable pressure method. ${ }^{35}$
A wide range of values for permeability and selectivity have been shown for PIM-1. ${ }^{43}$ For $\mathrm{N}_{2}$ and $\mathrm{CO}_{2}$ (the gases of interest in this paper), the permeabilities at $25{ }^{\circ} \mathrm{C}$ have been shown to be in the range of 92-353 Barrer $^{18,44}$ and 2300-6500 Barrer $^{18,43}$ for $\mathrm{N}_{2}$ and $\mathrm{CO}_{2}$ respectively, in agreement with our values after our first measurement of PIM-1 film at 9 days ageing (Fig. 10). The gas permeabilities of the PIM-1 films were reduced when postmodified pyrene-based additives. This can be attributed to the pyrene-based additives filling up free volume content of the PIM-1 matrix that consequently reduces the gas diffusivity coefficients. This is supported by the gas sorption data which shows reduced surface area for samples with higher additive content.

The gas permeabilities of PIM-1 are known to decrease over time as a function of polymer ageing.,45,46 Polymer ageing

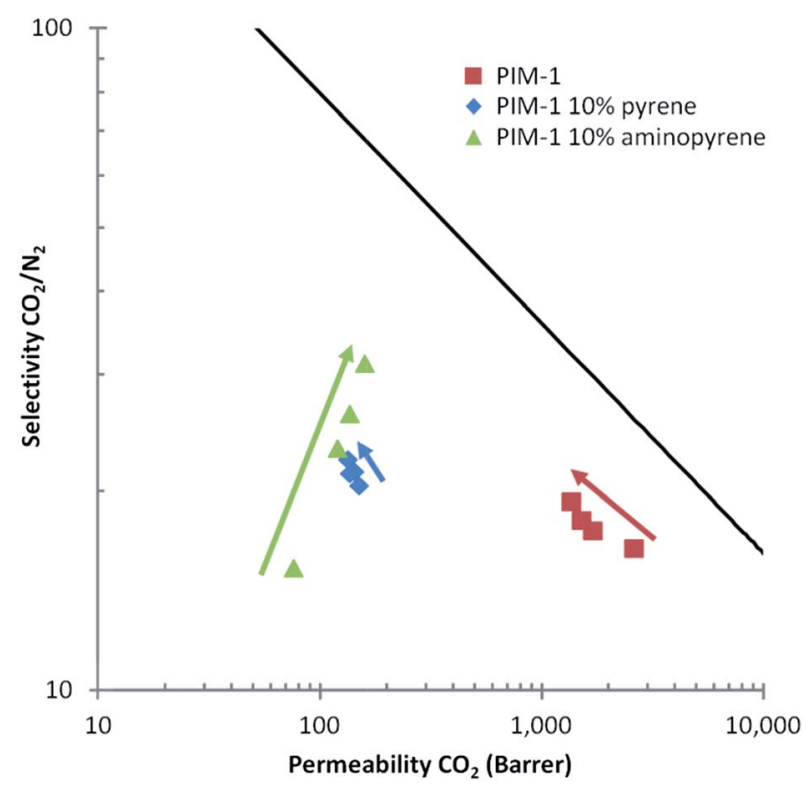

Fig. 10 Robeson plot for $\mathrm{CO}_{2} / \mathrm{N}_{2}$ selectivity versus permeability of $\mathrm{CO}_{2}$. Three samples are shown unmodified PIM-1, PIM-1 post-modified with 10\% pyrene and PIM-1 post-modified with 10\% 1-aminopyrene. The arrows indicate the change in the permeability and selectivity over time, the bottom of the arrow was at after 9 days of ageing, the intermediate data points were after 17 days and 35 days, while the top of the arrow indicates after 50 days of ageing. The line indicates the Robeson 2008 upper bound. ${ }^{49}$ 
occurs as polymer chains attempt to relax towards each other to achieve a thermodynamic equilibrium. We observe the same as trend commonly reported in literature, with the PIM-1 film displaying a decrease in permeability with increased ageing. When a PIM-1 film was post-modified with pyrene, we observed a slight decrease in the rate of ageing. Interestingly, in the case of the PIM-1 film post-modified with 1-aminopyrene, the ageing effect on the permeability was completely arrested and a slight increase in $\mathrm{CO}_{2}$ permeability was observed over time (Fig. 10). With physical aging, the pore sizes could decrease over time to an extent that the pore size favours $\mathrm{CO}_{2}$ sorption, resulting in increased enthalpy of $\mathrm{CO}_{2}$ adsorption. Other researchers have also shown that decreasing the pore volume of other porous materials such as metal-organic frameworks and polymers can lead to increased enthalpy of gas adsorption. ${ }^{47,48}$ Our permeability experiments suggest that the stronger charge-transfer interactions between PIM-1 and 1-aminopyrene (compared to pyrene) may be sufficient to physically crosslink the polymer locking the polymer chains in position, and this rigidification of the PIM-1 chains is the key to stop polymer ageing.

\section{Conclusions}

We have demonstrated an extremely facile and inexpensive method for modifying the gas sorption and physical properties of PIM-1. PIM-1 has been shown to interact with a number of PAHs, an extended planar conjugated system appeared to be necessary in order to induce sufficient attraction to the PIM-1 to cause precipitation. We demonstrate that blending pyrene as an additive with PIM-1 led to a dramatic reduction in nitrogen uptake (at $77 \mathrm{~K}$ ) while only leading to a minor loss of $\mathrm{CO}_{2}$ uptake (at $298 \mathrm{~K}$ ). In order to maintain a fully solution processable material, a post-modification strategy with pyrene and 1-aminopyrene was developed. Nanoindentation analysis of the PIM1 films post-modified with pyrene or 1-aminopyrene revealed that these samples had higher elastic moduli than unmodified PIM-1 films, evidence of the physical crosslinking of the PIM-1 chains. Gas sorption analysis of PIM-1 films post-modified with pyrene and 1-aminopyrene demonstrated that increasing the additive content had a greater effect on reducing the $\mathrm{N}_{2}$ uptake at $77 \mathrm{~K}$ than on lowering the $\mathrm{CO}_{2}$ uptake at $293 \mathrm{~K}$. The effect on the uptake of $\mathrm{N}_{2}$ at $293 \mathrm{~K}$ was less pronounced, although PIM-1 films post-modified with $11 \%$ pyrene or 1-aminopyrene displayed essentially no $\mathrm{N}_{2}$ uptake, these films displayed vastly improved gas sorption selectivities for $\mathrm{CO}_{2}$ over $\mathrm{N}_{2}$ compared to unmodified PIM-1 film.

Analysis of the $\mathrm{CO}_{2}$ and $\mathrm{N}_{2}$ gas permeabilities for the postmodified PIM-1 films suggested that while the use of pyrene based additives reduced the overall permeability of the film, the physical crosslinking effect produced by modification of PIM-1 film with $10 \%$ 1-aminopyrene was sufficient to stop the usual loss of permeability observed for unmodified PIM-1 with ageing over the 50 days tested.

The effect of blending electron-rich additives into PIM films was highly pronounced. Even only a few percent of inexpensive, commercially available additive (pyrene) was sufficient to significantly modify both the gas sorption properties, and physical characteristics of the film. Considering the widespread current interest in PIMs for practical applications, this opens up a new strategy for modifying PIM materials. There are now several PIM type polymers reported in the literature which combine porosity, solubility, and an electron-deficient repeating unit. However, the last few years have seen the reports of new porous polymer systems, based on repeating units of pyrene and other related $\mathrm{PAHs},{ }^{\mathbf{5 0}-52}$ which display similar porosity and solubility, but with electron-rich repeating units. For commercial non-porous polymers it is commonplace to blend a polymer with a small amount of co-polymer, or molecular additive, in order to tune physical properties such as glass transition temperature or stiffness. Our results show that a similar methodology could potentially be achieved in PIMs, fully realising the potential for processing that solubility gives these polymers in comparison to other porous materials.

\section{Acknowledgements}

The authors gratefully acknowledge the EPSRC for funding (EP/ H000925/1). In addition, they would like to thank the Centre of Materials Discovery for access to equipment and technical support, especially Dr Sean Higgins for performing GPC analysis. C. H. Lau acknowledges the support from the Science and Industry Endowment Fund, Australia. T. Ratvijitvech thanks Mahidol University, Thailand for Funding.

\section{Notes and references}

1 N. B. McKeown and P. M. Budd, Chem. Soc. Rev., 2006, 35, 675-683.

2 N. B. McKeown, ISRN Mater. Sci., 2012, 2012, 16.

3 P. M. Budd, B. S. Ghanem, S. Makhseed, N. B. McKeown, K. J. Msayib and C. E. Tattershall, Chem. Commun., 2004, 230-231.

4 P. M. Budd, N. B. McKeown, B. S. Ghanem, K. J. Msayib, D. Fritsch, L. Starannikova, N. Belov, O. Sanfirova, Y. Yampolskii and V. Shantarovich, J. Membr. Sci., 2008, 325, 851-860.

5 P. M. Budd, E. S. Elabas, B. S. Ghanem, S. Makhseed, N. B. McKeown, K. J. Msayib, C. E. Tattershall and D. Wang, Adv. Mater., 2004, 16, 456-459.

6 P. Li, T. S. Chung and D. R. Paul, J. Membr. Sci., 2013, 432, 50-57.

7 N. Du, G. P. Robertson, I. Pinnau and M. D. Guiver, Macromolecules, 2009, 42, 6023-6030.

8 N. Du, G. P. Robertson, J. Song, I. Pinnau and M. D. Guiver, Macromolecules, 2009, 42, 6038-6043.

9 T. Emmler, K. Heinrich, D. Fritsch, P. M. Budd, N. Chaukura, D. Ehlers, K. Rätzke and F. Faupel, Macromolecules, 2010, 43, 6075-6084.

10 D. Fritsch, G. Bengtson, M. Carta and N. B. McKeown, Macromol. Chem. Phys., 2011, 212, 1137-1146.

11 C. R. Mason, L. Maynard-Atem, N. M. Al-Harbi, P. M. Budd, P. Bernardo, F. Bazzarelli, G. Clarizia and J. C. Jansen, Macromolecules, 2011, 44, 6471-6479. 
12 S. Harms, K. Raetzke, F. Faupel, N. Chaukura, P. M. Budd, W. Egger and L. Ravelli, J. Adhes., 2012, 88, 608-619.

13 F. Y. Li, Y. Xiao, T.-S. Chung and S. Kawi, Macromolecules, 2012, 45, 1427-1437.

14 H. A. Patel and C. T. Yavuz, Chem. Commun., 2012, 48, 99899991.

15 S. Chen, W. Yi, J. Duhamel, K. Heinrich, G. Bengtson and D. Fritsch, J. Phys. Chem. B, 2013, 117, 5249-5260.

16 Q. Song, S. Cao, P. Zavala-Rivera, L. Ping Lu, W. Li, Y. Ji, S. A. Al-Muhtaseb, A. K. Cheetham and E. Sivaniah, Nat. Commun., 2013, 4, 1918.

17 N. Du, H. B. Park, G. P. Robertson, M. M. Dal-Cin, T. Visser, L. Scoles and M. D. Guiver, Nat. Mater., 2011, 10, 372-375.

18 P. M. Budd, K. J. Msayib, C. E. Tattershall, B. S. Ghanem, K. J. Reynolds, N. B. McKeown and D. Fritsch, J. Membr. Sci., 2005, 251, 263-269.

19 R. Swaidan, B. S. Ghanem, E. Litwiller and I. Pinnau, J. Membr. Sci., 2014, 457, 95-102.

20 C. R. Mason, L. Maynard-Atem, K. W. J. Heard, B. Satilmis, P. M. Budd, K. Friess, M. Lanč, P. Bernardo, G. Clarizia and J. C. Jansen, Macromolecules, 2014, 47, 1021-1029.

21 F. Y. Li, Y. Xiao, Y. K. Ong and T.-S. Chung, Adv. Energy Mater., 2012, 2, 1456-1466.

22 Q. Song, S. Cao, R. H. Pritchard, B. Ghalei, S. A. Al-Muhtaseb, E. M. Terentjev, A. K. Cheetham and E. Sivaniah, Nat. Commun., 2014, 5, 4813.

23 G. Dong, H. Li and V. Chen, J. Mater. Chem. A, 2013, 1, 46104630.

24 J. Ahn, W. J. Chung, I. Pinnau, J. S. Song, N. Y. Du, G. P. Robertson and M. D. Guiver, J. Membr. Sci., 2010, 346, 280-287.

25 A. F. Bushell, P. M. Budd, M. P. Attfield, J. T. A. Jones, T. Hasell, A. I. Cooper, P. Bernardo, F. Bazzarelli, G. Clarizia and J. C. Jansen, Angew. Chem., Int. Ed., 2013, 52, 1253-1256.

26 C. H. Lau, P. T. Nguyen, M. R. Hill, A. W. Thornton, K. Konstas, C. M. Doherty, R. J. Mulder, L. Bourgeois, A. C. Y. Liu, D. J. Sprouster, J. P. Sullivan, T. J. Bastow, A. J. Hill, D. L. Gin and R. D. Noble, Angew. Chem., 2014, 126, 5426-5430.

27 M. M. Khan, V. Filiz, G. Bengtson, S. Shishatskiy, M. M. Rahman, J. Lillepaerg and V. Abetz, J. Membr. Sci., 2013, 436, 109-120.

28 W. F. Yong, F. Y. Li, Y. C. Xiao, P. Li, K. P. Pramoda, Y. W. Tong and T. S. Chung, J. Membr. Sci., 2012, 407, 47-57. 29 W. F. Yong, F. Y. Li, T.-S. Chung and Y. W. Tong, J. Mater. Chem. A, 2013, 1, 13914-13925.
30 M. M. Khan, G. Bengtson, S. Shishatskiy, B. N. Gacal, M. M. Rahman, S. Neumann, V. Filiz and V. Abetz, Eur. Polym. J., 2013, 49, 4157-4166.

31 F. Herbst, D. Döhler, P. Michael and W. H. Binder, Macromol. Rapid Commun., 2013, 34, 203-220.

32 S. Burattini, B. W. Greenland, D. H. Merino, W. Weng, J. Seppala, H. M. Colquhoun, W. Hayes, M. E. Mackay, I. W. Hamley and S. J. Rowan, J. Am. Chem. Soc., 2010, 132, 12051-12058.

33 L. R. Hart, J. H. Hunter, N. A. Nguyen, J. L. Harries, B. W. Greenland, M. E. Mackay, H. M. Colquhoun and W. Hayes, Polym. Chem., 2014, 5, 3680-3688.

34 X. Li and B. Bhushan, Mater. Charact., 2002, 48, 11-36.

35 S. A. Stern, P. J. Gareis, T. F. Sinclair and P. H. Mohr, J. Appl. Polym. Sci., 1963, 7, 2035-2051.

36 Z. Huang, Y. Kim, T. Kim and M. Lee, Polym. Chem., 2013, 4, 268-271.

37 J. C. Barnes, M. Juríček, N. L. Strutt, M. Frasconi, S. Sampath, M. A. Giesener, P. L. McGrier, C. J. Bruns, C. L. Stern, A. A. Sarjeant and J. F. Stoddart, J. Am. Chem. Soc., 2012, 135, 183-192.

38 S. Brunauer, P. H. Emmett and E. Teller, J. Am. Chem. Soc., 1938, 60, 309-319.

39 J. Weber, N. Du and M. D. Guiver, Macromolecules, 2011, 44, 1763-1767.

40 J. Jeromenok and J. Weber, Langmuir, 2013, 29, 12982-12989.

41 Z. G. Wang, X. Liu, D. Wang and J. Jin, Polym. Chem., 2014, 5, 2793-2800.

42 W. E. Acree Jr and M. H. Abraham, Fluid Phase Equilib., 2002, 201, 245-258.

43 S. Thomas, I. Pinnau, N. Du and M. D. Guiver, J. Membr. Sci., 2009, 333, 125-131.

44 N. Du, G. P. Robertson, J. Song, I. Pinnau, S. Thomas and M. D. Guiver, Macromolecules, 2008, 41, 9656-9662.

45 F. Y. Li and T.-S. Chung, Int. J. Hydrogen Energy, 2013, 38, 9786-9793.

46 P. Bernardo, F. Bazzarelli, J. C. Jansen, G. Clarizia, F. Tasselli and C. R. Mason, Procedia Eng., 2012, 44, 874-876.

47 J. An and N. L. Rosi, J. Am. Chem. Soc., 2010, 132, 5578-5579. 48 W. Lu, D. Yuan, J. Sculley, D. Zhao, R. Krishna and H.-C. Zhou, J. Am. Chem. Soc., 2011, 133, 18126-18129.

49 L. M. Robeson, J. Membr. Sci., 2008, 320, 390-400.

50 G. Cheng, T. Hasell, A. Trewin, D. J. Adams and A. I. Cooper, Angew. Chem., Int. Ed., 2012, 51, 12727-12731.

51 G. Cheng, B. Bonillo, R. S. Sprick, D. J. Adams, T. Hasell and A. I. Cooper, Adv. Funct. Mater., 2014, 24, 5219-5224.

$52 \mathrm{X} . \mathrm{Wu}, \mathrm{H}$. Li, B. Xu, H. Tong and L. Wang, Polym. Chem., 2014, 5, 4521-4525. 